\title{
Understanding the Role of Monsoon Depressions on Intraseasonal Oscillations over Indian Sub-Continent
}

\author{
Pilli Suneetha*, Katru Naga Lakshmi, Ramlingeswara Rao Sai, Latha Peddada, \\ Dasari Melchi Zedek, Odury Bhanu Kumar \\ Department of Meteorology \& Oceanography, College of Science and Technology, Andhra University, Visakhapatnam \\ Email: *sunitha.pmet@gmail.com
}

How to cite this paper: Suneetha, P., Lakshmi, K.N., Sai, R.R., Peddada, L., Zedek, D.M. and Kumar, O.B. (2018) Understanding the Role of Monsoon Depressions on Intraseasonal Oscillations over Indian Sub-Continent. International Journal of Geosciences, 9, 236-253.

https://doi.org/10.4236/ijg.2018.94015

Received: March 4, 2018

Accepted: April 27, 2018

Published: April 30, 2018

Copyright $\odot 2018$ by authors and Scientific Research Publishing Inc. This work is licensed under the Creative Commons Attribution International License (CC BY 4.0).

http://creativecommons.org/licenses/by/4.0/

(c) (i) Open Access

\begin{abstract}
Summer monsoon and its synoptic, meso-scale systems provide $80 \%$ of total annual rainfall over India. Monsoon depressions are weak, low-pressure circulation within the monsoon trough that forms in the head Bay of Bengal and moves northwestward and westward across the Indian sub-continent during summer monsoon season. Another convective system from this planetary scale circulation is the Intraseasonal Oscillation (ISO) also occurs in the daily mode. It is very important to study the impact of monsoon depressions in synoptic scale on ISOs through its strength, frequency and duration. In the recent decades, frequency of monsoon depressions and sea surface temperature over head Bay is decreasing while the intensity is increasing over Bay of Bengal. The study brings out the relationship between the ISOs and monsoon depressions over Bay of Bengal through their structure and movement for the period 1990-2014. Composites of monsoon and no monsoon depression days are calculated and found that rainfall is mainly occupied over Kerala and Interior Peninsula within the range of $10-50 \mathrm{~cm}$ during monsoon depression days. Relative vorticity brings out that the shallower layer of convergence mainly from $1000-850 \mathrm{hPa}$ level and a deeper layer of weak divergence above it is mainly associated with the depression. Next, thermodynamic structure of monsoon depression and its intensity is directly proportional to the increasing of CAPE. Wavelet spectrum also indicates the intraseasonal oscillations are very active during monsoon depression days. Finally this study helps to bring out plausible reasons through circulations, dynamic and thermodynamic characteristics involved in monsoon depression days in association with the ISOs.
\end{abstract}

\section{Keywords}

Depressions, ISOs, CAPE, Relative Vorticity 


\section{Introduction}

Precipitation in the summer monsoon season accounts for more than $80 \%$ of India's annual rainfall and is crucial for the region's agriculture and economy [1]. The monsoon climate is traditionally characterized by large amount of seasonal rainfall and reversal of wind direction [2]. Most importantly this rainfall is the major source of fresh water to various human activities such as agriculture and irrigation purposes. Large fraction of annual rainfall occurs during the summer monsoon season, with two distinct maxima. One is located over the Bay of Bengal with rainfall extending northwestward into eastern and central India, and the other along the west coast of India where the lower level moist wind meets the Western Ghats [3]. Various weather systems such as tropical cyclones and weak disturbances contribute to monsoon rainfall [4]. Among these systems, the most efficient rain-producing system is known as the Indian monsoon depression [2]. They originate near the head Bay of Bengal during July and August; they form over the central Bay of Bengal in the months of June and September. They move west-northwestward along the monsoon trough towards the heat-low system over the northwest India and Pakistan. Monsoon depressions have been the topic of intense with scientific investigation over last 100 years. Eliot [5] recognized monsoon lows and depressions and these synoptic systems form within the monsoon trough often in the north and central Bay of Bengal. A few of the depressions (about $20 \%)$ even intensify into cyclonic storm over northern Bay and rapidly weaken as they move over land. As most of the lows/depressions form over the northern Bay of Bengal, organized convection occurs first near the coast. The prominent role of the monsoon trough at sea level and in the lower troposphere in monsoon processes was recognized by [6]. Synoptic analyses have shown that cyclonic whirls of different intensity and life duration are embedded within the monsoon trough [7]. Many studies have focused on the climatology, mechanisms of formation, dynamical instability, movement, rainfall potential and a variety of facts associated with them. Sikka [8] examined five years each of good and drought monsoon seasons and suggested that the number of total low pressure systems (LPSs) and LPS days within a season, and not the number of depressions and depression days. Mooley and Shukla [9] [10] examined LPSs and its days have interannual and decadal variability in association with seasonal rainfall over India for the period 1888-1983. In recent years there has been a revival of interest in the study of LPSs [11] [12] [13]. The average life duration of these low pressure systems is about five days for those forming over the Bay of Bengal and three days for those forming over Indian landmass combined barotropic, baroclinic and CISK instability theory controls the monsoon cyclogenisis [14]. It is generally believed that many of these systems from insitu over warm waters of the Bay of Bengal under the upper troposphere divergent flow of the Tibetan high and upper troposphere easterly waves [15]. 
Large meridional shear of the eastward component of winds and high cyclonic vorticity at low levels over the monsoon trough region favor growth of these instabilities. Recent studies [16] [17] [18] have shown that the spatial structure of monsoon ISO is such that they strengthen the seasonal mean circulation in one phase while weakening it in the opposite phase. Therefore, the monsoon ISO has the potential to modulate the frequency of occurrence of LPS by alternately enhancing and weakening the zonal wind shear and low level cyclonic vorticity in the monsoon trough (MT). Indication of association between ISO regimes and synoptic activity during the Indian summer monsoon was presented in some previous studies [19] [20] [21]. Prajeesh [22] identified a significant decreasing trend of annual monsoon depression frequency making $80 \%$ landfall to the south of $20^{\circ} \mathrm{N}$ on the east coast of India for the period 1979-2010. The findings gave that mid tropospheric relative humidity is decreasing since 1950 and it is one of the appropriate reason for the weakening of monsoon depressions over India. Wide literature [23] [24] suggested that the majority of monsoon depressions that form over the Bay of Bengal can be attributed to the regenesis of westward propagating residual lows of typhoons, of tropical storms, or of other tropical disturbances from the western tropical Pacific_-South China Sea (WTP_SCS) region. This suggestion was later substantiated by Saha et al., [25] through a comprehensive synoptic and statistical analysis of the sea level pressure tendency over northern Indo-China. Hypothetically, any mechanism causing a variation in the frequency of tropical cyclones and of other weather disturbances in the WTP-SCS region may result in a corresponding change in the westward propagation of residual lows and the formation of monsoon depressions over the Bay of Bengal. Two such possible mechanisms are interannual and intraseasonal variations of large-scale summer circulation in the WTP-SCS region induced by 1) the interannual variation of the sea surface temperature (SST) in the eastern tropical Pacific and 2) the northward migration of the 30 - 60-day monsoon trough/ridge from the equator to around $20^{\circ} \mathrm{N}$. With the above information, the present study emphasis the role of monsoon depression in association with ISO for the study period, 1990-2014.

\section{Data and Methodology}

Daily averaged NCEP/NCAR global wind, precipitable water, relative humidity, omega, sea level pressure, monsoon depression tracks data from IMD $\left(2.5^{\circ}\right.$ lat $\times$ $2.5^{\circ}$ long) during 21 year period (1990-2014) have been used in the present study. The IMD daily gridded rainfall datasets are collected at 0.5 lat/long resolution [26]. Next, tracks of monsoon depressions from the IMD are taken to observe movement of monsoon depressions from the Bay of Bengal to Indian subcontinent for the period 1990-2014.

We have calculated the monsoon depression days (178) and no monsoon depression days (2872) from 1990-2014. With rainfall we have plotted the spatial 
and temporal maps of the rainfall to identify the highest and lowest amount of rainfall during monsoon and no monsoon depression days. Same thing have been applied for the all the parameters: precipitable water, relative humidity and sea level pressure data to identify the synoptic condition during monsoon depression days over the Bay of Bengal associated with the intraseasonal oscillations. Wavelet analysis is used to find out the periodicity, number and intensity of intraseasonal oscillations by using interactive wavelet plot available through the website http://paos.colorado.edu/research/wavelets/. Monsoon depression day's tracks have been drawn to examine the movement of the track in excess and deficient monsoon rainfall years. The monsoon depression days are less compare no monsoon depression days.

\section{Results and Discussions}

\subsection{Frequency of Monsoon Depressions}

Monsoon depressions are the primary rain bearing systems during summer monsoon season over India. Figure 1 depicts the five year running average of frequency of monsoon depression over Bay of Bengal during summer monsoon season for the period 1951-2013. The trend line is evaluated and the corresponding equation is $y=-0.0854 X+6.688$ where $X$ is the frequency of monsoon depressions. The root mean square error is 0.86 which is significant at $1 \%$ level.

\subsection{Dynamic/Thermodynamic Characteristics of Monsoon Depression}

From Figure 2, it is interesting to note that the rainfall distribution observed that the rainfall is peak in the Gujarat $(>80 \mathrm{~cm})$ where the extreme rainfall events are more due to orographic lifting of moisture air from the Arabian Sea. During the monsoon depression days the rainfall is more scattered along from Kerala to interior parts of south peninsular India in and around east coast of India and the rainfall range is $10-50 \mathrm{~cm}$ (Figure 2). The rainfall is observed along the Gujarat, Maharashtra and some parts of northeast India and the rainfall varies in between $10-70 \mathrm{~cm}$ during no monsoon depression days. The spatial distribution of rainfall varies $10-100 \mathrm{~cm}$ over India in monsoon and NMD days. Further Figure 3 indicates that the precipitable water vapor $(46 \mathrm{~mm})$ is occupied over head Bay of Bengal and along the east coast of India during monsoon depression days while preciptable water is more pronounced over central Bay of Bengal and also along the Gujarat area $(50 \mathrm{~mm})$ during no monsoon depression days.

The significant phenomenon noticed associated with the depression is the shallower layer of convergence below the $850 \mathrm{hPa}$ level and a deeper layer of weak divergence above it. This result is a very characteristic feature of the monsoon depression with low level of non divergence approximately around $850 \mathrm{hPa}$ level. The series of low level circulation vortices are mainly observed along the east coast of India with peak intensity over Head Bay of Bengal during monsoon 


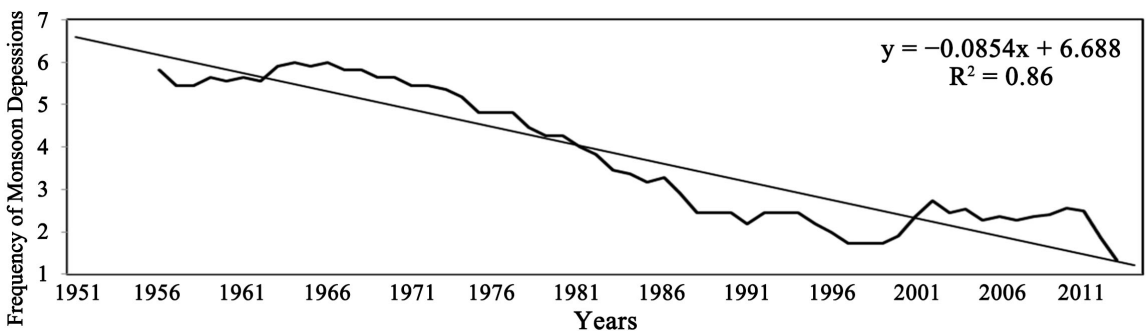

Figure 1. 5-year running average of frequency of monsoon depressions over Bay of Bengal for the period 1951-2013.
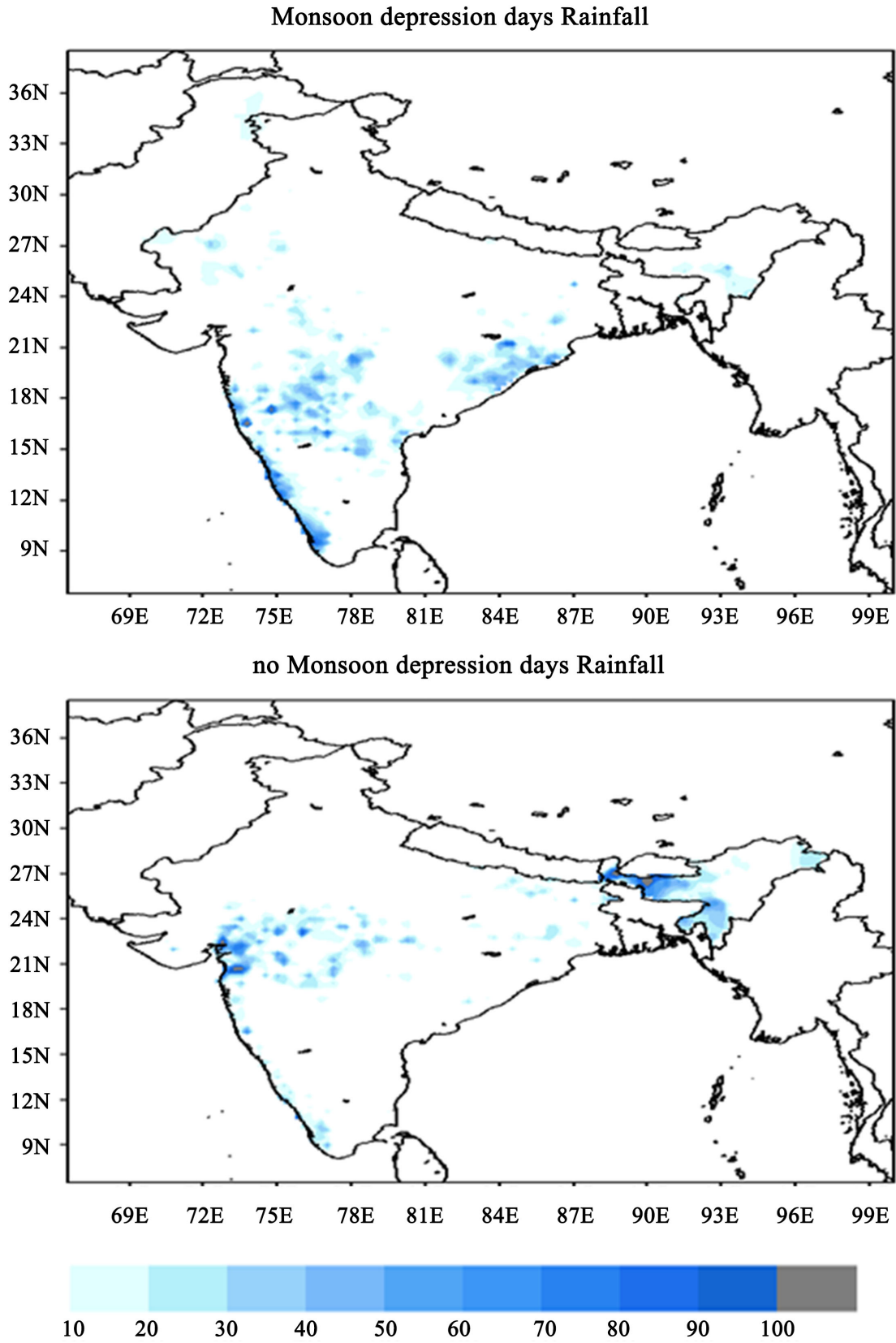

Figure 2. IMD high resolution gridded rainfall for monsoon depression days and no monsoon depression days for the period 1990-2007 (Top: Monsoon depression days, Bottom: no Monsoon depression days). 


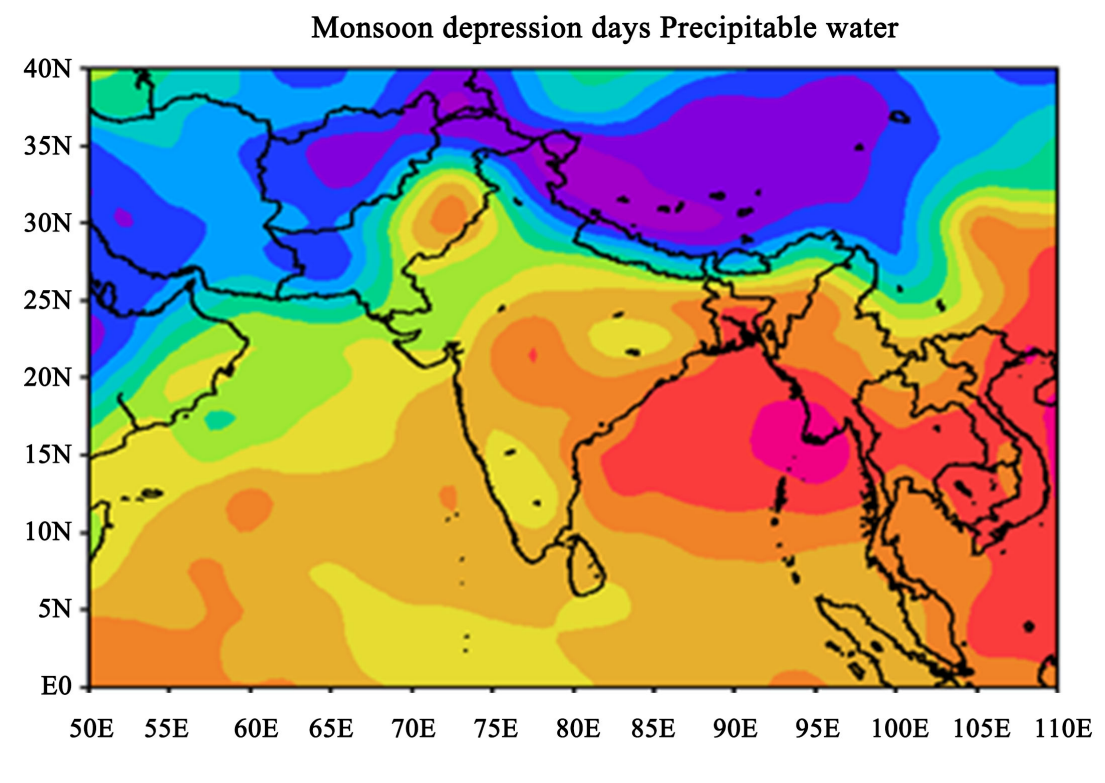

no Monsoon depression days Precipitable water

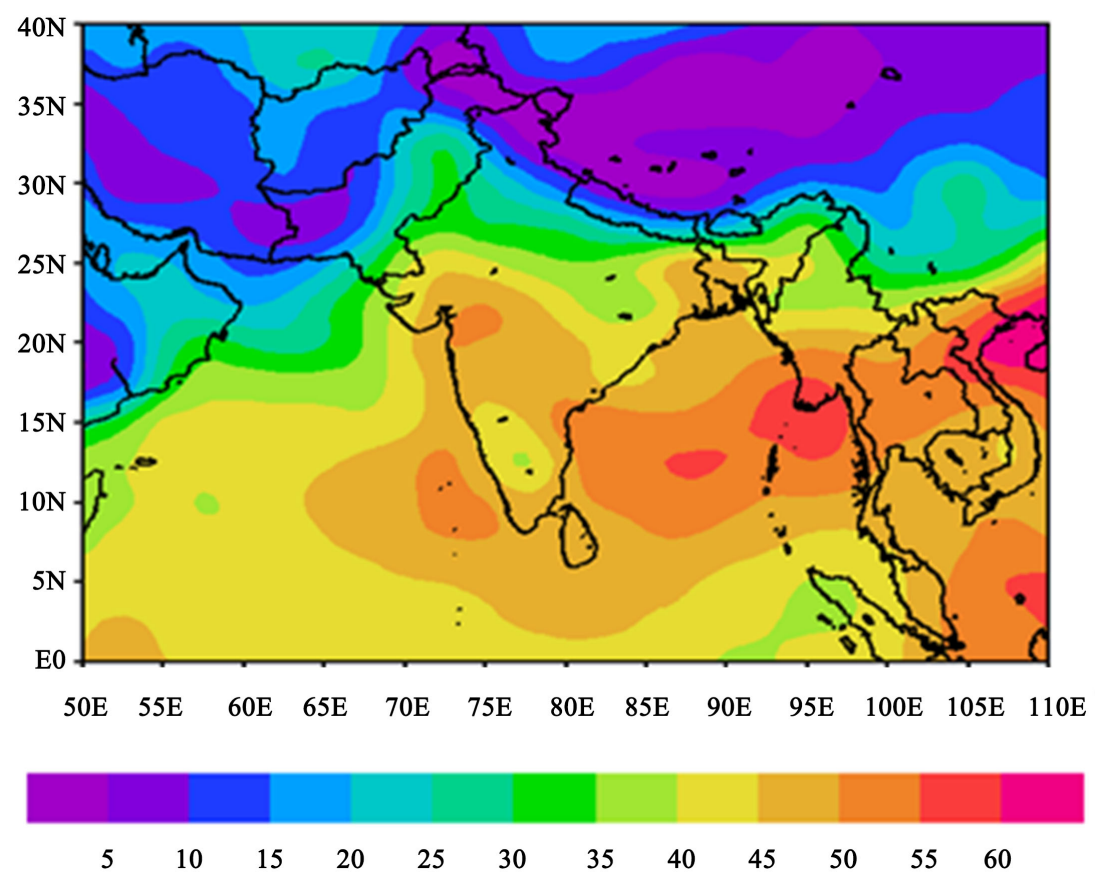

Figure 3. Same as above figure except for preciptable water $(\mathrm{mm} / \mathrm{g})$.

depression days (Figure 4). At the same time weak vortices are observed with an intensity $10 \mathrm{~m} / \mathrm{s}$ during no monsoon depression days. The wind shear is very weak during no monsoon depression days than the monsoon depression days.

Relative humidity indicates that the saturation is mainly observed over $5^{\circ} \mathrm{N}$ to $16^{\circ} \mathrm{N}(\sim 80 \%)$ during monsoon depression days (Figure 5). During no monsoon depression day's relative humidity is low (40\% - 50\%) from lower to middle level of the atmosphere. Relative humidity values maintaining the same values over Bay of Bengal and Arabian sea during monsoon and no monsoon depression days. High relative vorticity $0.25 \times 10$ at $850 \mathrm{hPa}$ marks the core of the 
Monsoon depression days Relative vortcity

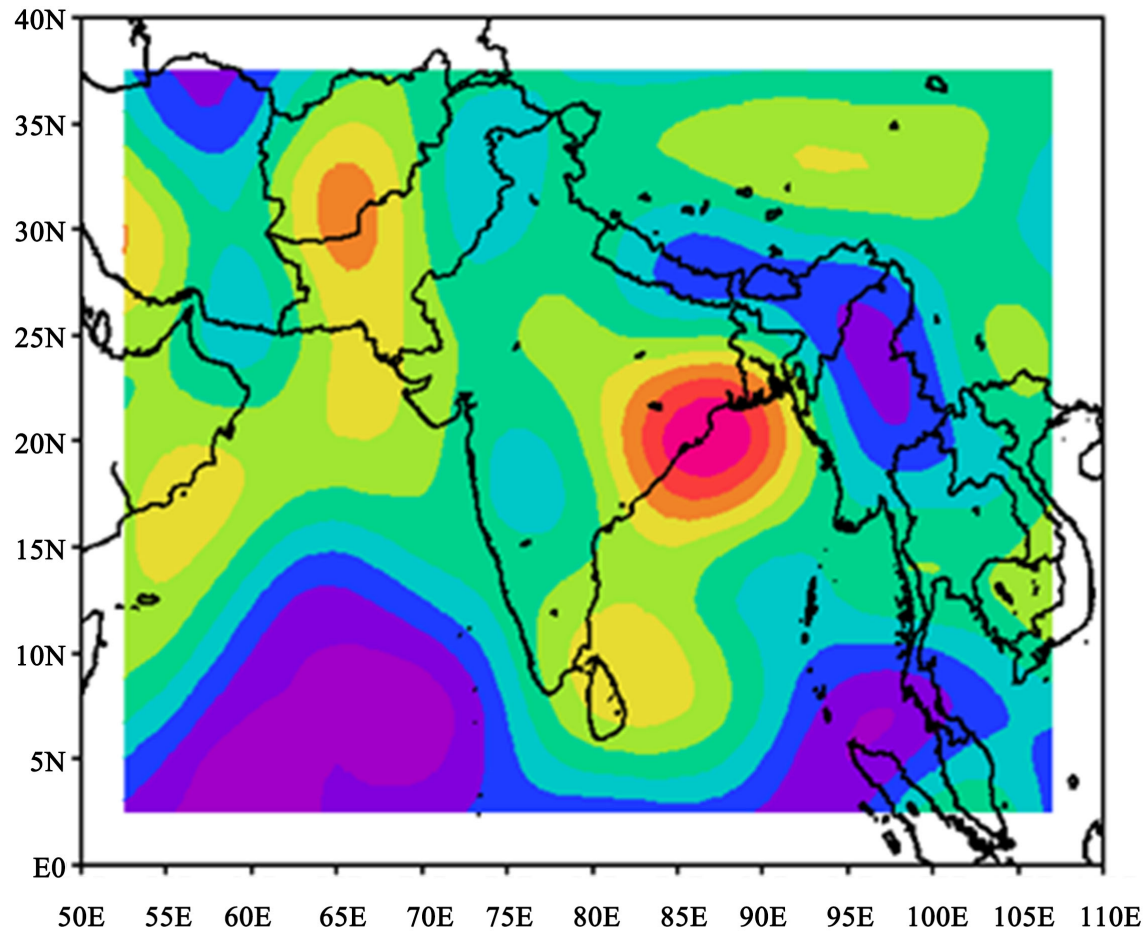

no Monsoon depression days Relative vortcity

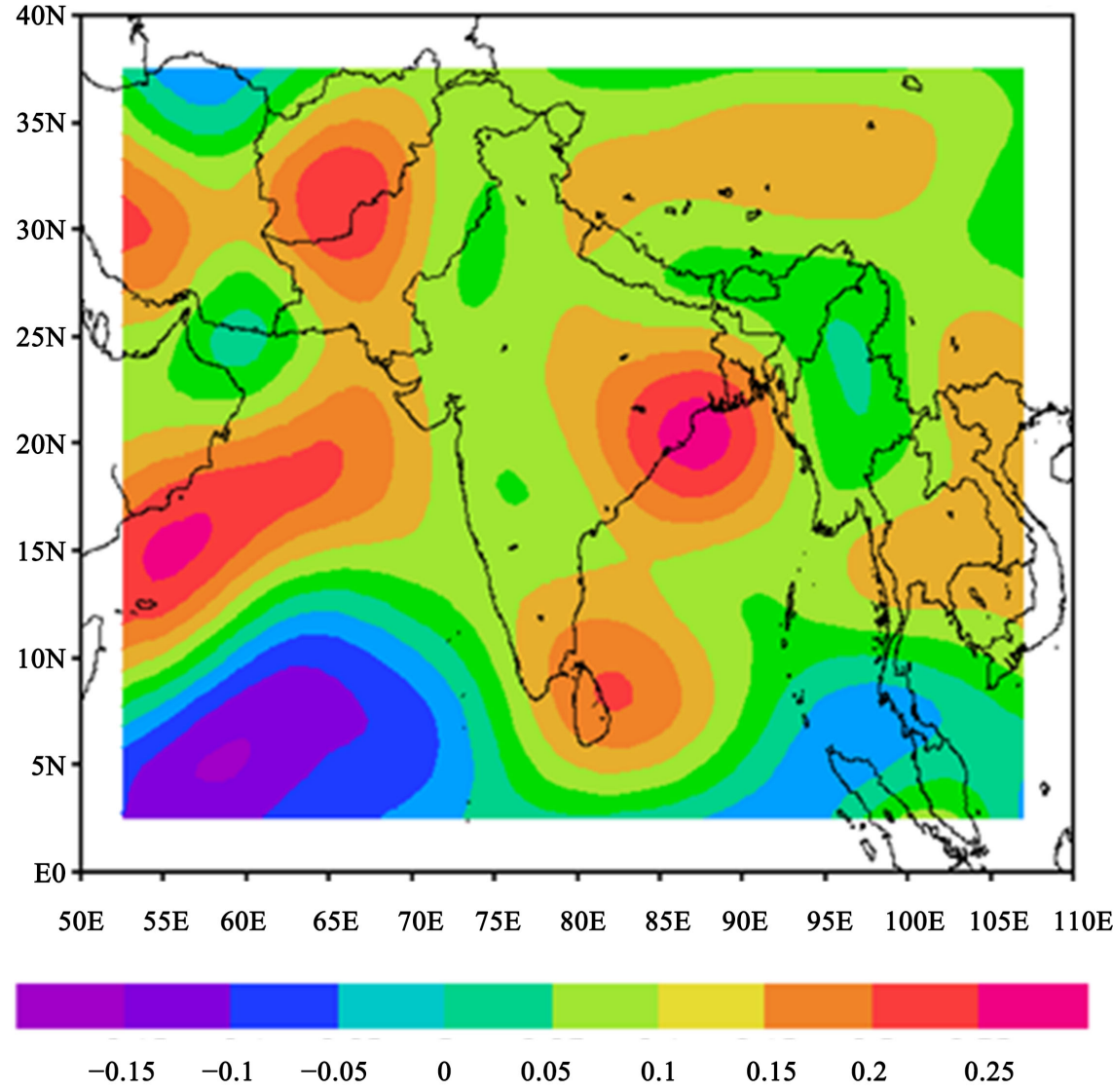

Figure 4. Same as above figure except for relative vorticity $(\mathrm{m} / \mathrm{s})$ at $850 \mathrm{hPa}$. 
Monsoon depression days Relative humidity

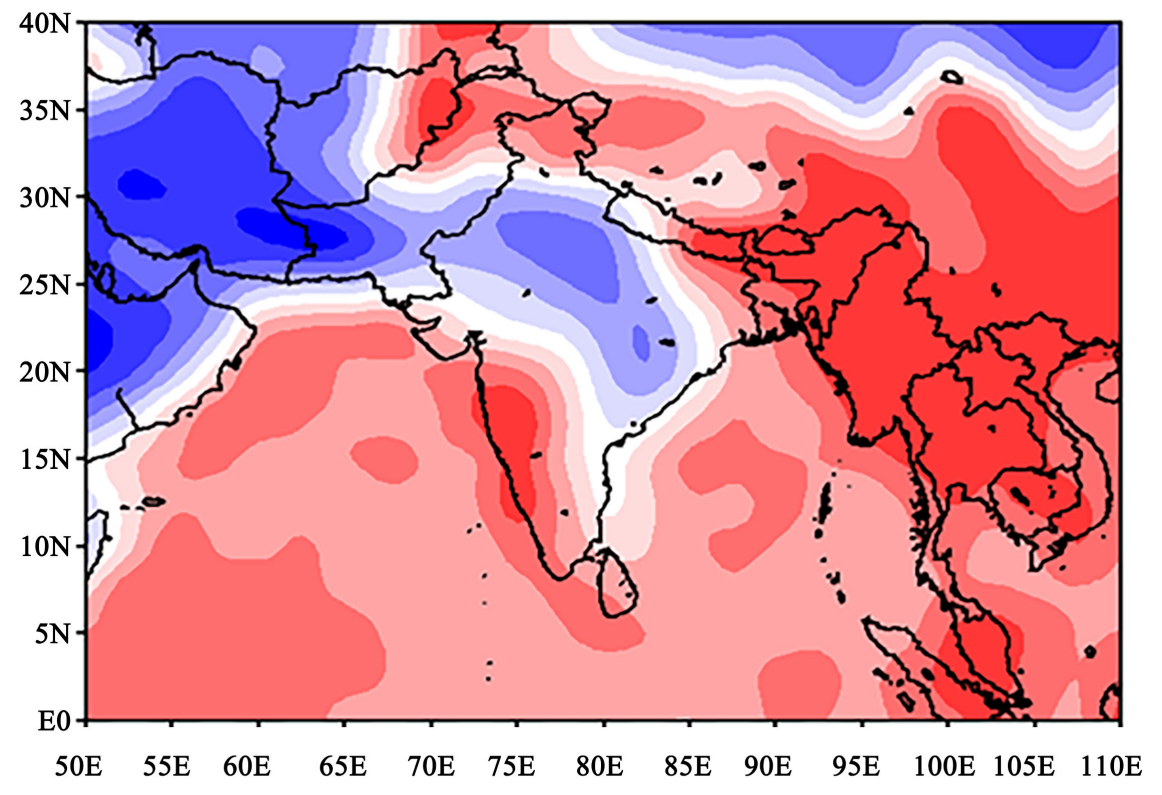

no Monsoon depression days Relative humidity

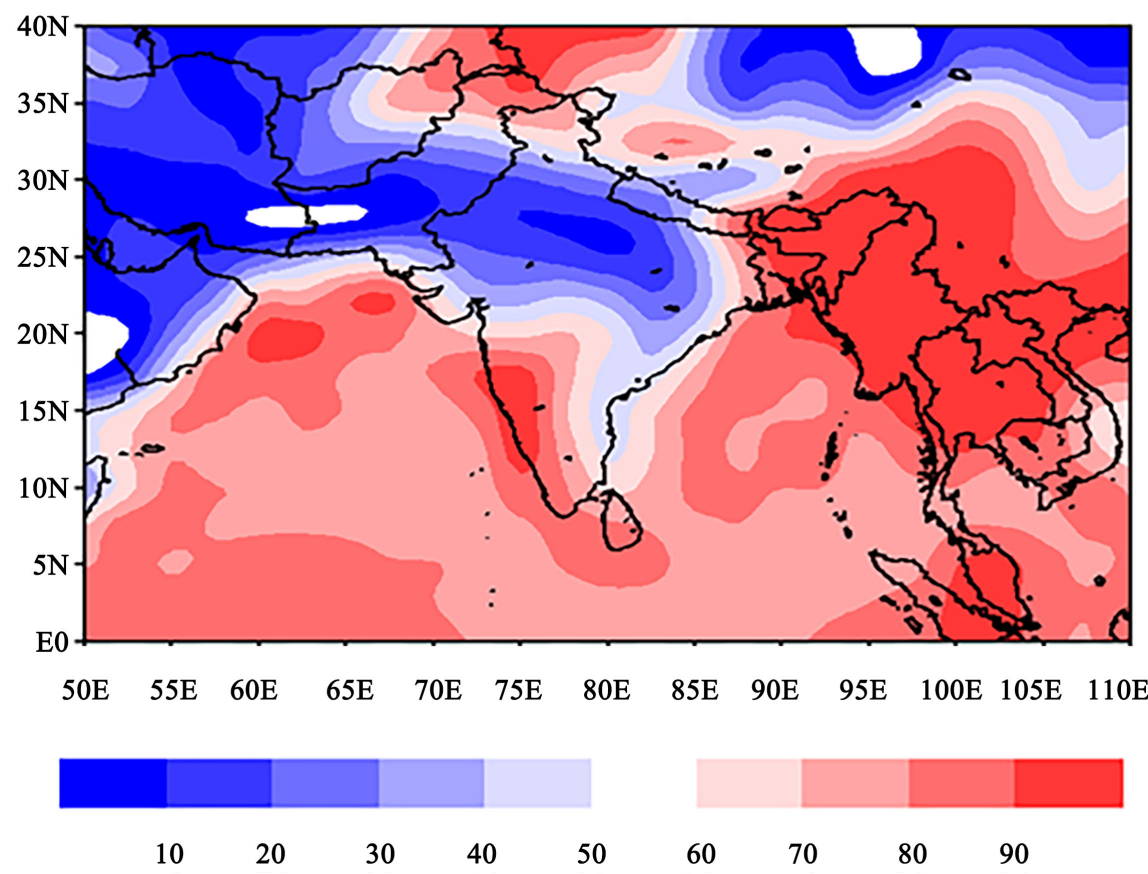

Figure 5. Same as above figure except for relative humidity (\%).

monsoon depression during monsoon depression days. High relative vorticity helps to maintain low surface pressure. Positive values of relative vorticity are associated with regions of low pressure. As air parcels move through the region of maximum vorticity, their spin slows resulting in divergence. Divergence at the $500 \mathrm{mb}$ level removes mass from the air column causing a drop in surface barometric pressure. In turn, lower pressure at the surface results in convergence promoting rising air parcels in the column. These rising air parcels contribute to 
the formation of precipitation so prevalent with monsoon depressions. During no monsoon depression days most of the places are negative relative vorticity over India compare to monsoon depression days.

The cyclonic circulation is mainly prevails over head bay of Bengal and the intensity of south esterlies are more $(16.5 \mathrm{~m} / \mathrm{s})$ during monsoon depression days while weak westerlies prevails $(12 \mathrm{~m} / \mathrm{s})$ during no monsoon depression days (Figure 6). The tropical easterly jet (TEJ) stream is very active $(22.4 \mathrm{~m} / \mathrm{s})$ and is located at $5^{\circ} \mathrm{N}$ during monsoon depression days than no monsoon depression days (Figure 7). The location of TEJ further shifted southwards during no monsoon depression days. Tropical eastrly jet is stronger during monsoon depresssion days compare to no monsoon depression days.

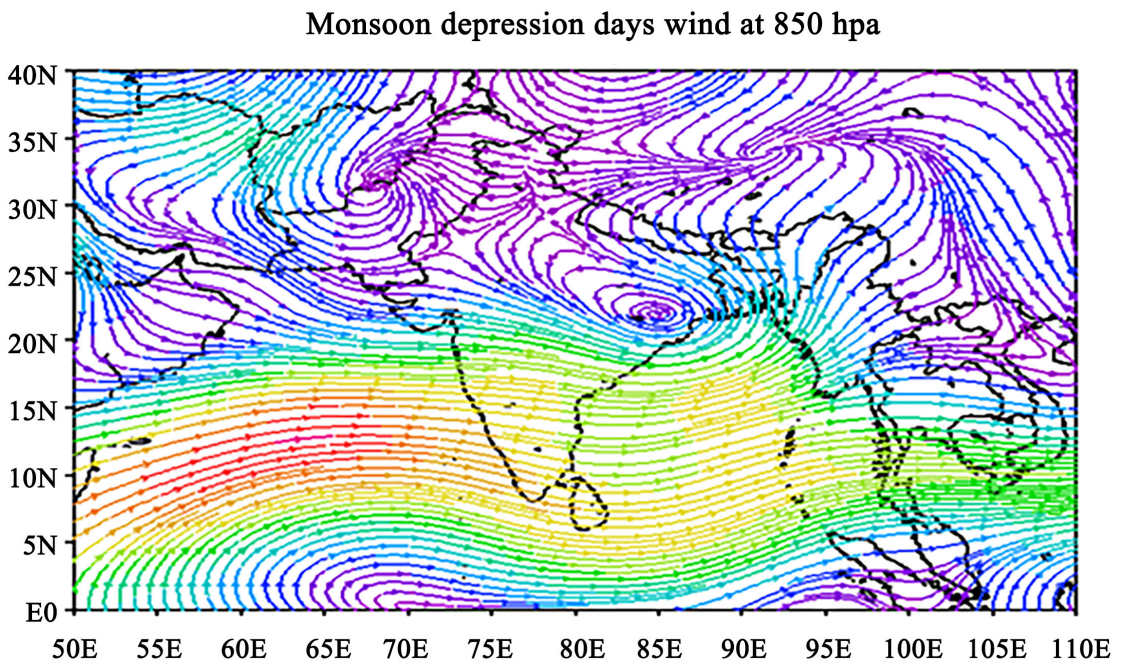

no Monsoon depression days wind at $850 \mathrm{hpa}$

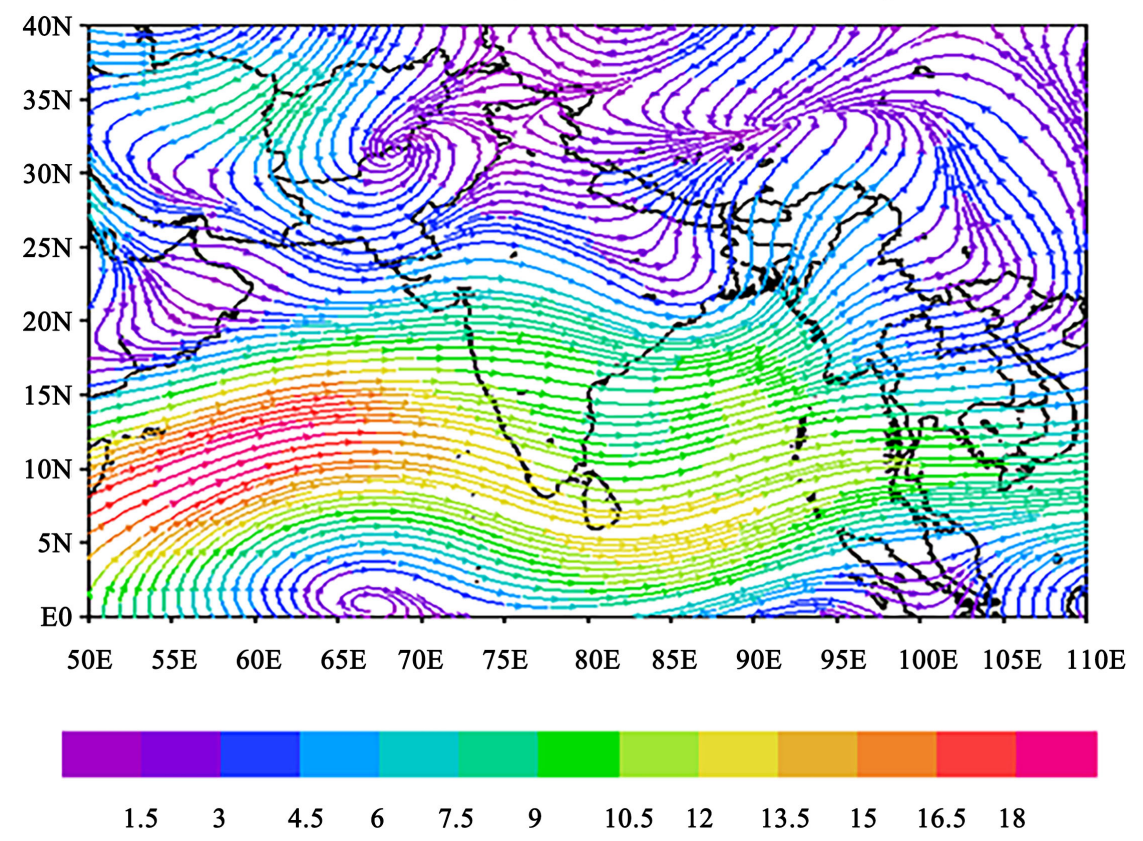

Figure 6. Same as above figure except for low level circulation at $850 \mathrm{hPa}$ level $(\mathrm{m} / \mathrm{s})$. 


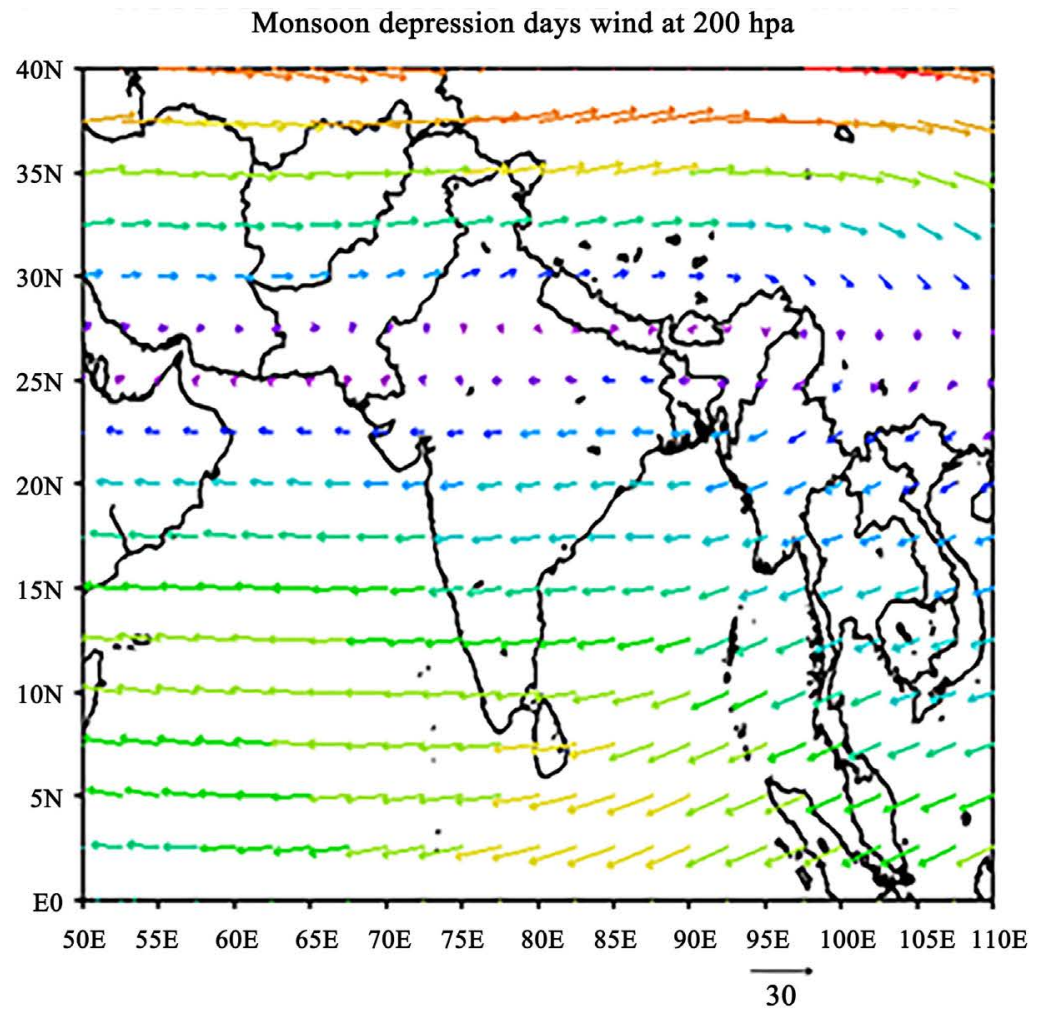

no Monsoon depression days wind at $200 \mathrm{hpa}$

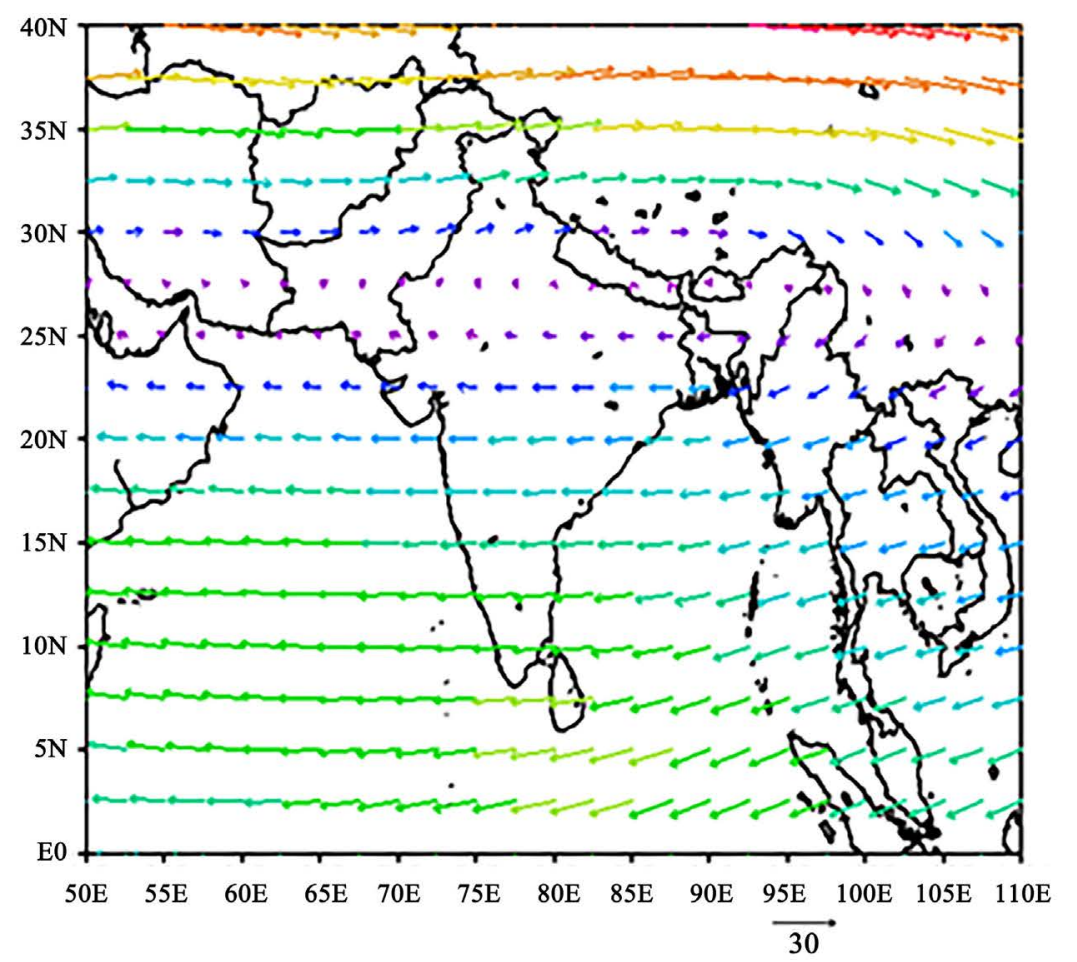

$\begin{array}{llllllllllll}2.8 & 5.6 & 8.4 & 11.2 & 14 & 16.8 & 19.6 & 22.4 & 25.2 & 28 & 30.8 & 33.6\end{array}$

Figure 7. Same as above figure except for higher level circulation at $200 \mathrm{hPa}$ level (m/s). 
Monsoon depression days from 1990-2014, the SLP it is observed that two closed isobars of pressure 1998 and $1000 \mathrm{hPa}$ centered at N.E coast and head Bay of Bengal from the IMD criteria it is where there are two closed isobars with difference of $2 \mathrm{hPa}$ there is a depression formation in that region. Over the central B.O.B and south peninsular India the isobars are extending with the SLP of 1002 - 1006 hpa (Figure 8). So we can say that a trough is formed along the east coast and B.O.B which indicates that there is a good monsoon rainfall.
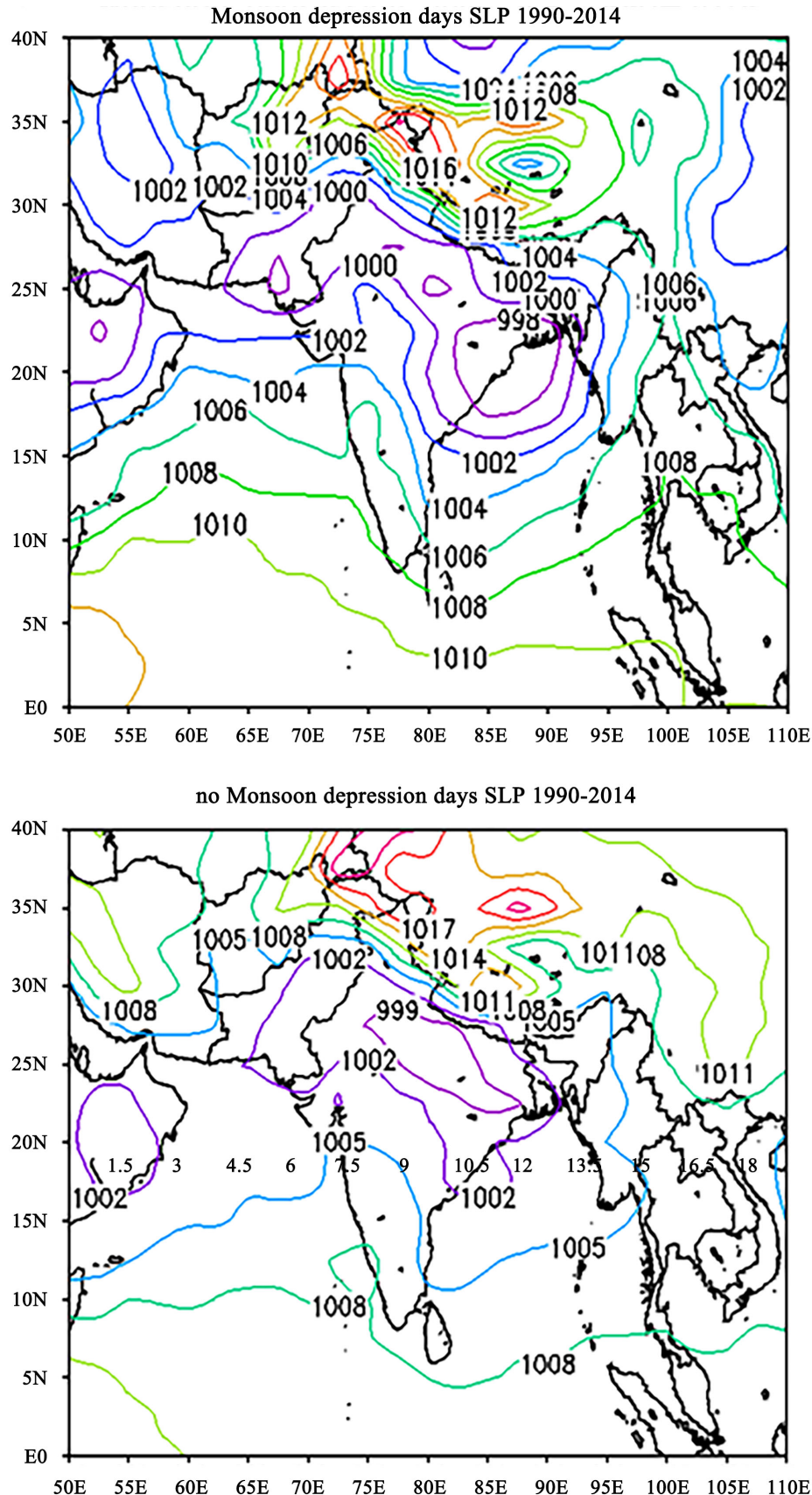

Figure 8. Sea level pressure for the monsoon depression days and no monsoon depression days for the period 1990-2014. (Top: Monsoon depression days, Bottom: no Monsoon depression days). 
The $\omega$-distribution in the lower troposphere shows a centre of maximum upward motion around the $900-850 \mathrm{mb}$ level. As the depression intensifies, the upward motion is always present on the west side of the depression centre. The presence of upward motion at lower levels is mainly due to frictional forces and other baroclinic and dynamical forces (Figure 9). Convective available potential energy indicates that thermodynamic energy is more where the monsoon depression is originated (Figure 10). The rainfall during monsoon depressions indicates that rainfall is more closely occupy in the southwestern sector of monsoon depression centre.
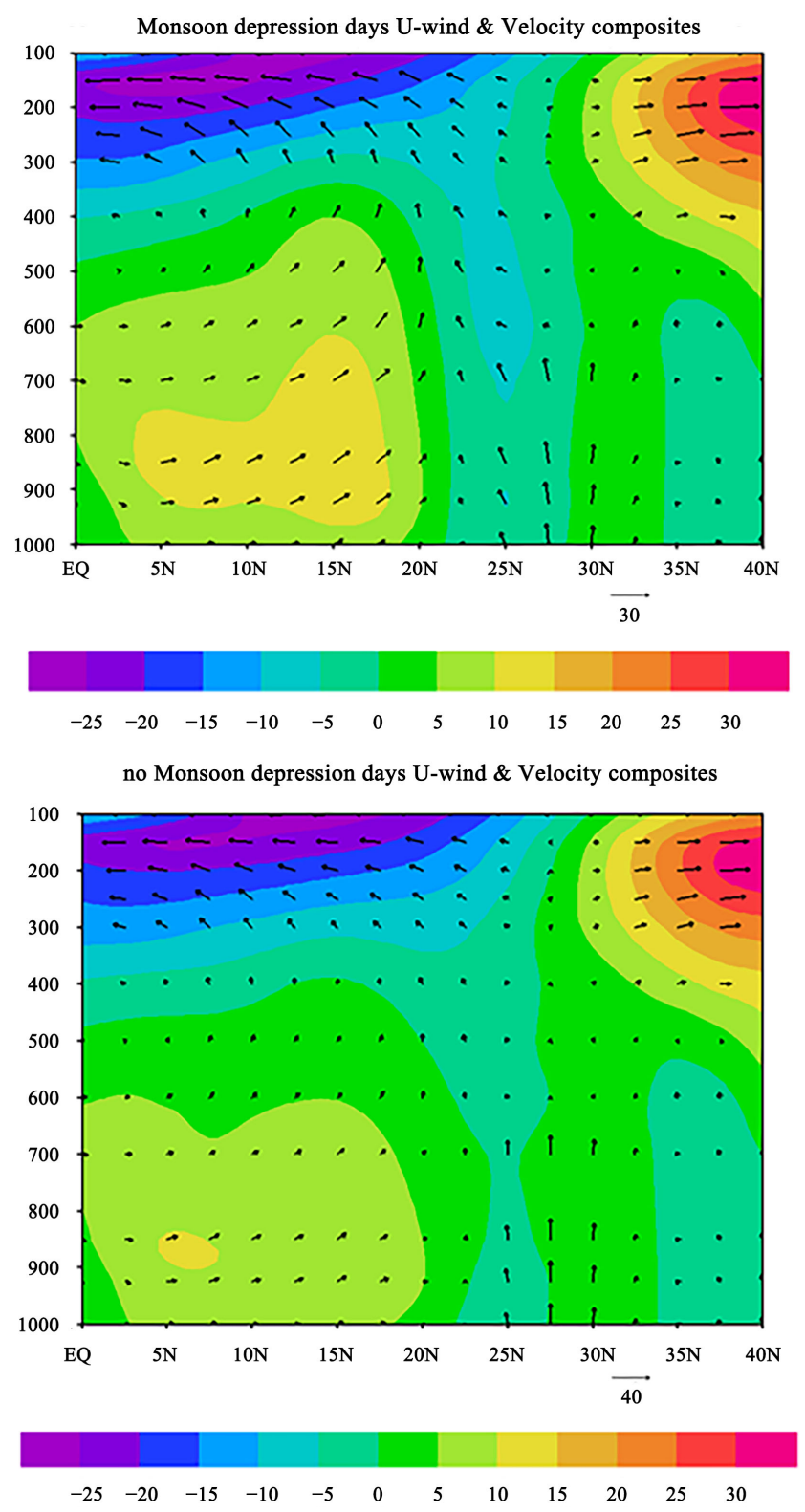

Figure 9. U-wind and vertical velocity composites for the monsoon depression days and no monsoon depression days for the period 1990-2014. (Top: Monsoon depression days, Bottom: no Monsoon depression days). 
Monsoon depression days CAPE 1990-2014
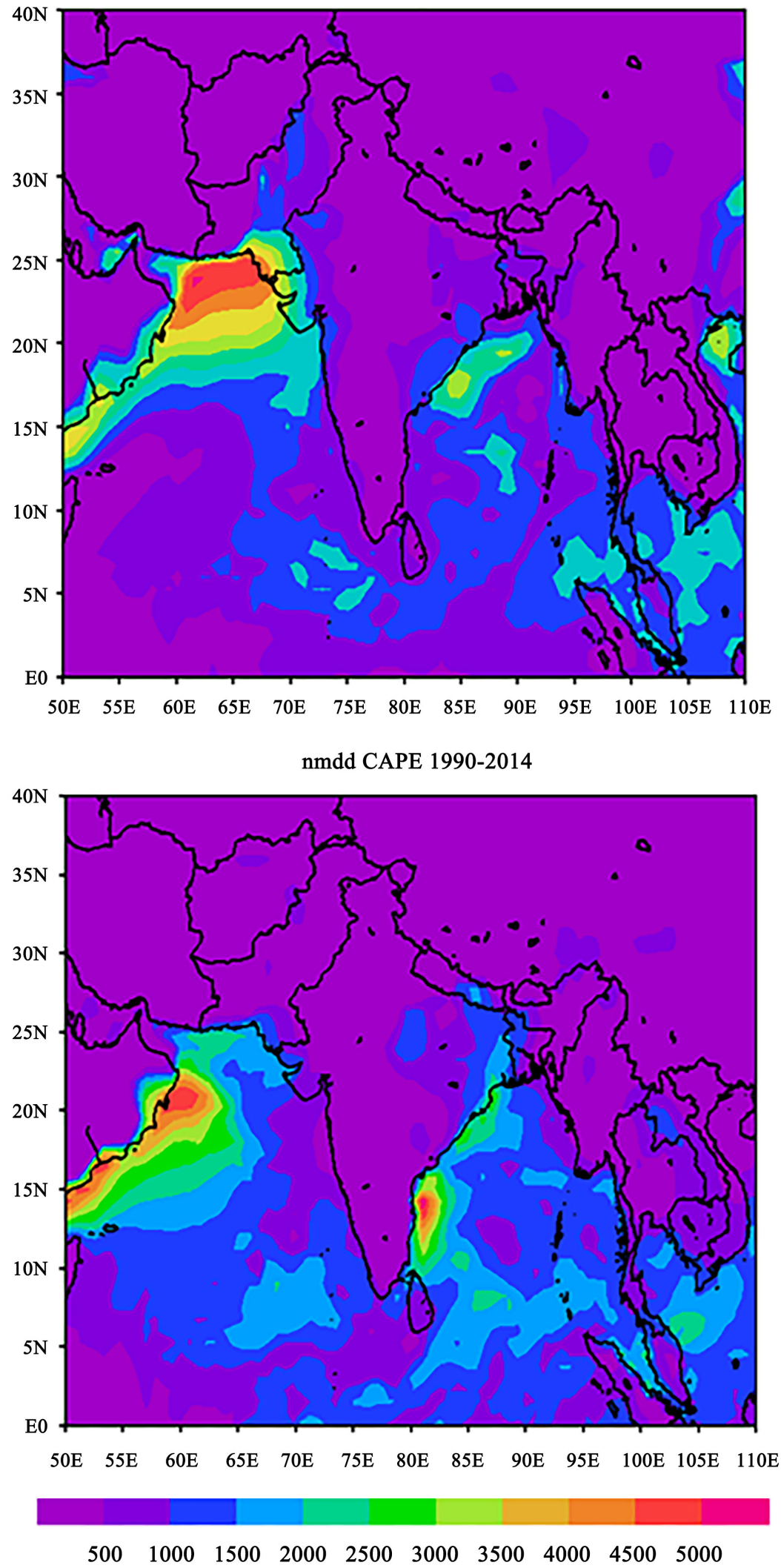

Figure 10. CAPE for monsoon depression days and no monsoon depression days during 1990-2014. 


\subsection{Movement of the MDs in Active and Deficient Years}

The composites of monsoon depression with available data are drawn for the study period during summer monsoon season. Figure 11 indicates the monsoon depression frequency is more during active monsoon years than the deficient years. There are nine monsoon depressions are formed in active while three in deficient years. The movement of the monsoon depression is in northwest ward and southward during active monsoon years while the movement of MDs through northward direction during deficient years. This analysis infers that more number of monsoon depressions are mainly associated with monsoon trough along the Gangetic plains and southward shift from its normal position during active monsoon years. During deficient years the monsoon depressions are prevails over west Bengal and Bangladesh where the monsoon trough is mainly occupied at the foot hills of the Himalayas.

Wavelet spectrum indicates the intra-seasonal oscillations are very active during monsoon depression days. More number of oscillations are seen in the June month there are four high frequency oscillations (10 - 20-day). In the month of July, august the frequency and intensity of oscillations are less. In September there is high intensity of oscillations 10 - 20 day is extended in to 30 to 60 day oscillation (Figure 12). The same is applied for no monsoon depression days. Wavelet spectrum indicates the intra-seasonal oscillations are inactive during no monsoon depression days. In June, three oscillations with very short duration ( 1 - 10 day) and two 30 - 60 day oscillations with high intensity are observed. In July one 10 - 20 day oscillation and in August no oscillation is present. In September, there is one oscillation of high intensity for a long duration i.e. extended to 10 - 20 to 30 - 60 oscillation. From the analysis it is evident that 10 20 days oscillations are more prominent in active monsoon years and these are mainly associated with short duration of synoptic systems and trough activity. During deficient years the low frequency (30 - 60) oscillations are observed with no synoptic systems.

\section{Summary and Conclusion}

Monsoon depressions and Intraseasonal oscillations both are internally coupled ocean atmosphere interacting systems provides significant contribution of summer monsoon rainfall over India. Monsoon depression (178) and no monsoon depression (2080) days are calculated from the available life period of monsoon depressions over Bay of Bengal. It is pertinent that the frequency of monsoon depressions is decreasing over Bay of Bengal. In addition, the SSTs over Head Bay of Bengal also decrease with no significant trend. Anomalous SST provides that equatorial Indian Ocean warming play a significant role for generating the cyclogenesis of monsoon depressions. The spatial distribution of summer monsoon rainfall is mainly observed over southern peninsular India during monsoon depression days. The monsoon depression associated extreme rainfall events $>12.5 \mathrm{~cm}$ are mainly occupied over Jharkhand and some parts of 
west coast of India. Dynamic and Thermodynamic variables insights that probable reasons for providing the moisture transport from the Indian ocean to head Bay of Bengal. Intraseasonal oscillation like 10 - 20 is very active during monsoon depression days while 30 - 60 day oscillations are in no monsoon depression days. Later the study extended for active and deficient monsoon years through circulations features at 850 and $200 \mathrm{hPa}$ level. The monsoon depressions frequency is more in active rather than deficient years.
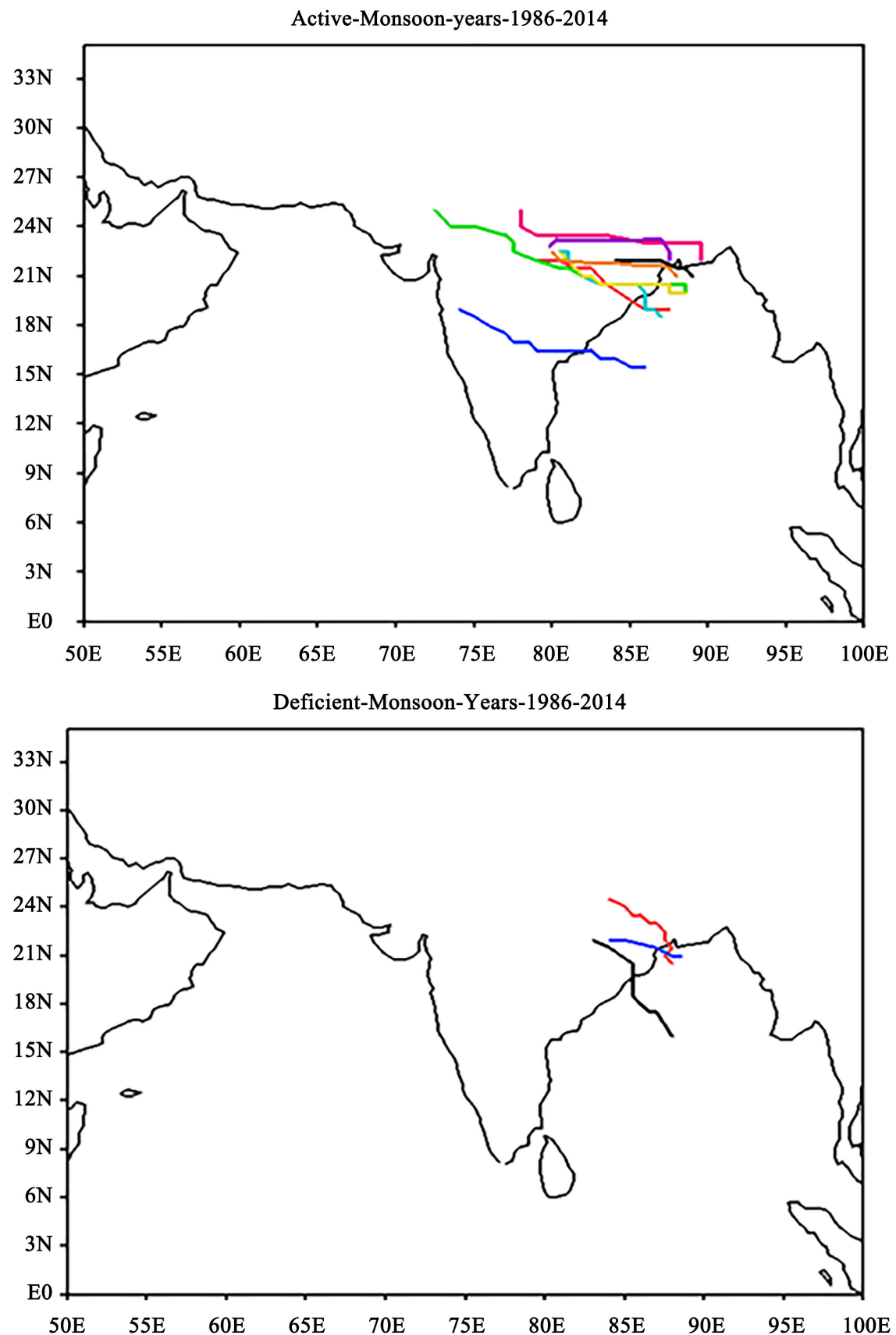

Figure 11. Composites of monsoon depression tracks of during active monsoon years $(1988,1990,1994,2007,2013)$ and deficient monsoon years $(1986,1987,2002,2004,2009)$ during 1990-2014. 
a. Zonal wind at 850 during monsoon depression days
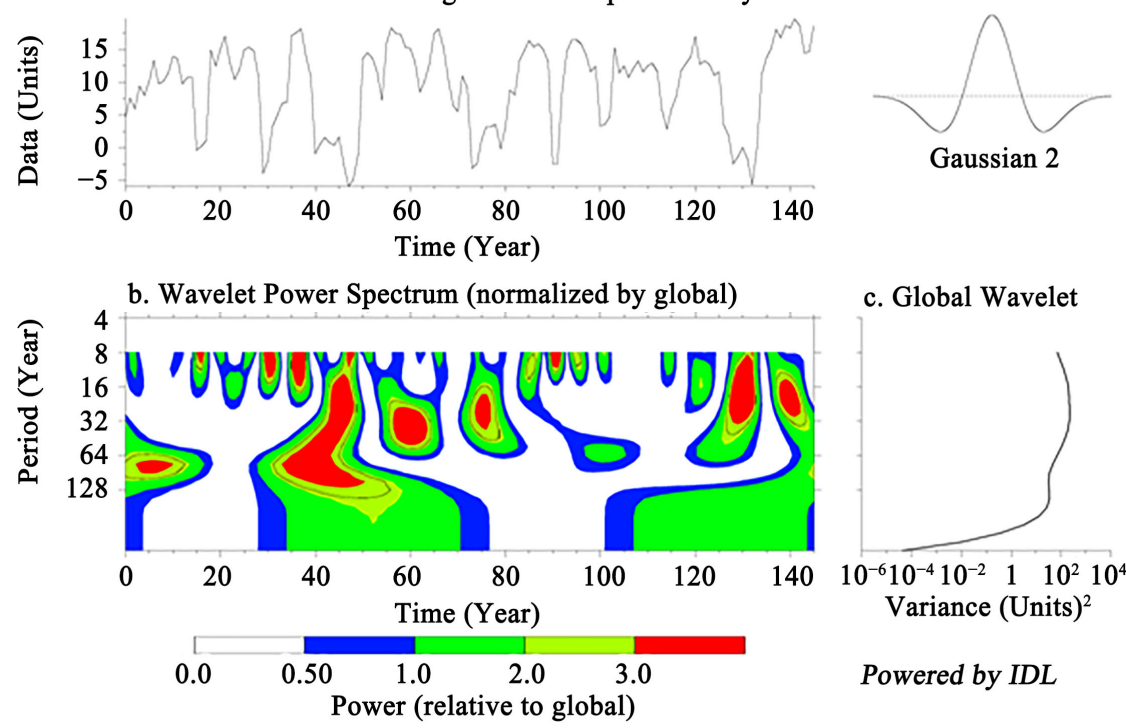

c. Global Wavelet
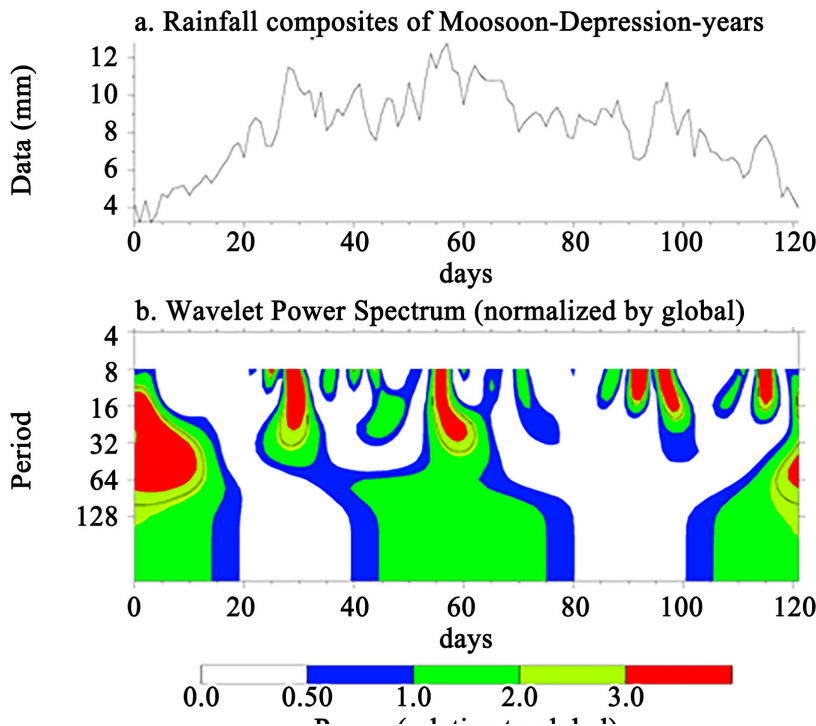

c. Global Wavelet

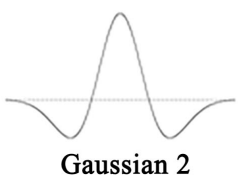

Figure 12. ISOs with Zonal wind at $850 \mathrm{hPa}$ level $(\mathrm{m} / \mathrm{s})$ and rainfall $(\mathrm{mm})$ for monsoon depression days during 1990-2007.

\section{Acknowledgements}

The authors are thankful to the NCEP/NCAR team and India Meteorological Department for providing the datasets. The second author is grateful to the Department of Science \& Technology, Government of India, New Delhi for their financial support through DST-INSPIRE fellowship.

\section{References}

[1] Ding, Y. and Sikka, D.R. (2006) Synoptic Systems and Weather. The Asian Monsoon, Springer, Berlin, Heidelberg, 131-201.

https://doi.org/10.1007/3-540-37722-0_4

[2] Krishnamurti, T.N. (1979) Tropical Meteorology. Secretariat of the World Meteorological Organization, Geneva. 
[3] Saha, K. Bavardeckar, S.N. (1977) Moisture Flux across the West of India and Rainfall during the Southwest Monsoon. Quarterly Journal of the Royal Meteorological Society, 103, 370-374.

[4] Ramage, C.S. (1971) Monsoon Meteorology. Academic Press, New York, 1971.

[5] Eliot, J. (1884) Accounts of Southwest Monsoon Storms Generated in the Bay of Bengal during 1877-1888. India Meteorological Department, New Delh, 217-448.

[6] Blandford, H.F. (1886) Rainfall of India. India Meteorological Department, 2, 217-448.

[7] Mukherjee, A.K. and Shyamala, B. (1978) Distant Effects of Monsoon Depressions on Weather over West Rajasthan. Indian Journal of Meteorology, Hydrology \& Geophysics, 29, 47-53.

[8] Sikka, D.R. and Gadgil, S. (1980) On the Maximum Cloud Zone and the ITCZ over Indian, Longitudes during the Southwest Monsoon. Monthly Weather Review, 108, 1840-1853. https://doi.org/10.1175/1520-0493(1980)108<1840:OTMCZA >2.0.CO;2

[9] Mooley, D.A. and Shukla, J. (1987) Characteristics of the Westward-Moving Summer Monsoon Low Pressure Systems over the Indian Region and Their Relationship with the Monsoon Rainfall. Department of Meteorology, Center for Ocean-Land-Atmosphere Interactions, University of Maryland, College Park.

[10] Mooley, D.A. and Shukla, J. (1989) Main Features of the Westward-Moving Low Pressure Systems which Form over the Indian Region during the Summer Monsoon Season and Their Relation to the Monsoon Rainfall. Mausam, 40, 137-152.

[11] Kumar, J.R. and Dash, S.K. (2001) Interdecadal Variations of Characteristics of Monsoon Disturbances and Their Epochal Relationships with Rainfall and Other Tropical Features. International Journal of Climatology, 21, 759-771. https://doi.org/10.1002/joc.628

[12] Patwardhan, S.K. and Bhalme, H.N. (2001) A Study of Cyclonic Disturbances over India and the Adjacent Ocean. International Journal of Climatology, 21, 527-534.

[13] Jadhav, S.K. (2002) Summer Monsoon Low Pressure Systems over the Indian Region and Their Relationship with the Sub-Divisional Rainfall. Mausam, 53, 177-186.

[14] Shukla, J. (1978) CISK-Barotropic-Baroclinic Instability and the Growth of Monsoon Depressions. Journal of the Atmospheric Sciences, 35, 495-508. https://doi.org/10.1175/1520-0469(1978)035<0495:CBBIAT>2.0.CO;2

[15] Koteswaram, P.P. and George, C.A. (1958) On the Formation of Monsoon Depressions in the Bay of Bengal. Indian Journal of Meteorology and Geophysics, 9, 9-22.

[16] Webster, P.J., Magana, V.O., Palmer, T.N., Shukla, J., Tomas, R.A., Yanai, M.U. and Yasunari, T. (1998) Monsoons: Processes, Predictability, and the Prospects for Prediction. Journal of Geophysical Research: Oceans, 103, 14451-14510. https://doi.org/10.1029/97JC02719

[17] Goswami, B.N. and Moha, R.A. (2001) Intraseasonal Oscillations and Interannual Variability of the Indian Summer Monsoon. Journal of Climate, 14, 1180-1198. https://doi.org/10.1175/1520-0442(2001)014<1180:IOAIVO>2.0.CO;2

[18] Sperber, K.R., Slingo, J.M. and Annamalai, H. (2000) Predictability and the Relationship between Subseasonal and Interannual Variability during the Asian Summer Monsoon. Quarterly Journal of the Royal Meteorological Society, 126, 2545-2574. https://doi.org/10.1002/qj.49712656810

[19] Murakami, T., Nakazawa, T. and He, J. (1984) On the 40 - 50 Day Oscillation during 1979 Northern Hemisphere Summer. Part I: Phase Propagation. Journal of the Meteorological Society of Japan, 62, 440-468. 
[20] Murakami, T., Chen, L.X. and Xie, A. (1986) Relationship among Seasonal Cycles, Low-Frequency Oscillations, and Transient Disturbances as Revealed From Outgoing Long Wave Radiation Data. Monthly Weather Review, 114, 456-465.

[21] Yasunari, T. (1981) Structure of an Indian Summer Monsoon System with Around 40-Day Period. Journal of Meteorological Society of Japan, 59, 336-354.

[22] Prajeesh, A.G., Ashok, K. and Rao, D.B. (2013) Falling Monsoon Depression Frequency: A Gray-Sikka Conditions Perspective. Scientific Reports, 3, Article No. 2989. https://doi.org/10.1038/srep02989

[23] Koteswaram, P. and Rao, N.B. (1963) Formation and Structure of Indian Summer Monsoon Depressions. Australian Meteorological Magazine, 41, 2-75.

[24] Krishnamurti, T.N., Molinari, J., Pan, H.L. and Wong, V. (1977) Downstream Amplification and Formation of Monsoon Disturbances. Monthly Weather Review, 105, 1281-1297.

https://doi.org/10.1175/1520-0493(1977)105<1281:DAAFOM>2.0.CO;2

[25] Saha, K., Sanders, F. and Shukla, J. (1981) Westward Propagating Predecessors of Monsoon Depressions. Monthly Weather Review, 109, 330-343.

https://doi.org/10.1175/1520-0493(1981)109<0330:WPPOMD>2.0.CO;2

[26] Rajeevan, M. and Bhate, J. (2009) A High Resolution Daily Gridded Rainfall Datasets (1971-2005) for Mesoscale Meteorological Studies. Current Science, 96, 558-562. 